\title{
Cứ lâu lâu lại gặp cụ Markov và suy nghĩ về lòng biết ơn
}

\author{
Vương Quân Hoàng
}

Hà Nội, 14-02-2022

Bài viêt này tôi viêt cho bản thân mình, nhu một lời tụ nhủ về giá trị của lòng biết onn. Khi nào quên mất giá trị ấy, thì cố nhớ đến tổn thất không thể khắc phục được một khi không còn được nhận ánh sáng của hiểu biêt và sự tử tến nưa. Điêu đó thật vô cùng tai hại, vì thếkhông bao giờ nên xảy ra.

Trong thời gian dài sống hơn 50 năm trên đời, tôi "gặp" rất nhiều con người vĩ đại làm nên lịch sử, khoa học và tiến bộ công nghệ, thay đổi tích cực đời sống nhân loại. Việc gặp gỡ ấy hẳn nhiên phải nhờ sách giáo khoa, báo chí, và sau này là sách chuyên khảo, ấn phẩm học thuật, và giờ là các nguồn tư liệu Internet, v.v.. Ngoài ra, còn học từ những người thầy đã giúp mình hiểu biết, trưởng thành, thậm chí đem lại cho bản thân cơ hội sống (tiền bạc, bằng cấp, trí khôn, v.v..).

Có lẽ chẳng thể liệt kê được hết, vì thời nào cũng có những bậc vĩ nhân đóng góp lớn lao. Việc có dịp biết đến một tên tuổi giúp ta tò mò tìm hiểu, đọc kỹ hơn và biết thêm cả những câu chuyện, giai thoại thú vị xung quanh cuộc đời ấy. Thường các giai thoại có chút hài hước lại khiến ta nhớ lâu hơn. Ví dụ chuyện Newton đãng trí đi hai chiếc giây khác nhau, hay Marktwain đối đáp tài tình sâu cay, giễu cợt thói xấu con người. Có những chuyện thì về kỳ tích gây sửng sốt, như Euler sau khi qua đời 50 năm, thì Viện hàn lâm Khoa học Nga mới đăng hết nổi số công trình toán học ông đã viết xong mà chưa kịp đăng, và ông viết nên trong lúc đã bị mù. Những chuyện này gây ấn tượng và việc tìm tòi thông tin đôi khi rất tình cờ, và không có gì liên quan tới công việc.

Trái lại, có vĩ nhân thì trực tiếp liên quan tới công việc trong những giai đoạn nhất định, thì có khi lại chẳng có mấy dịp tìm tòi. Cụ thể đối với tôi là nhà toán học Nga Andrey Markov (1856-1922). Dòng họ Markov này nhờ Wikipedia [1] tôi mới biết là đã sản sinh ra nhiều nhà toán học xuất sắc. Còn trực tiếp với đại danh Markov, thì mối liên hệ chủ yếu là quá trình Markov, tính chất Markov, xích Markov, và những khái niệm ứng dụng liên quan. 
Việc "gặp" cụ Markov thực chất là đã tự hàm chứa sự biết ơn với đóng góp sâu xa, nền tảng từ rất lâu trước đây của cụ. Nói đúng ra là phải vái cụ, chứ cái chữ "gặp" có phân... hỗn hào. Nhà toán học kỳ tài đó vừa là tiền nhân, vĩ nhân và ân nhân.

Năm 2001, tôi gặp cụ trong lúc nghiên cứu và ứng dụng thuật toán trên C++ cho bài toán option pricing qua giải phương trình vi phân riêng Black-Scholes bằng xấp xỉ [2].

Những năm 2005-2007, trong thời kỳ vẫn đang đi tìm câu trả lời về đường đi lâu dài cho việc nghiên cứu, lại có dịp gặp trong vài ấn phẩm [3-4].

... Thời gian trôi qua, đến giai đoạn 2017-2019, khi chuẩn bị phương pháp xử lý dữ liệu cho nghiên cứu và sau đó xuất bản chương trình bayesvl trên $R$ thì lại gặp lại cụ Markov ở cái cụm từ viết tắt kinh điển, thuộc hàng quen thuộc bậc nhất thế giới ngày nay, MCMC [5]. Kể từ khi [5] có mặt trên CRAN tới nay, mỗi năm, trung tâm nghiên cứu của tôi đều gặp và vái cụ rất nhiều bận, và thực tế là còn mong nhiều hơn thế nữa.

Vừa rồi, tôi gọi là "vái" cụ Markov. Đó là lối nói cho thoải mái, còn gọi đúng thì là lòng biết ơn. Nhánh khoa học tâm lý nghiên cứu về lòng biết ơn tới nay đã tồn tại cả thế kỷ, và ngày càng có những kết quả lý thú. Chẳng hạn, theo Kleiman et al. (2013), thì sự biết ơn có tác dụng tích cực với sức khỏe tâm lý con người, và thậm chí làm giảm rủi ro trâm cảm, khởi sinh ý định tự tử [6]. Điều này chắc chắn có liên quan tới nội dung trong Emmons (2007) cho rằng lòng biết ơn khiến cho con người hạnh phúc hơn (và vì thế khoa học về lòng biết ơn chính là khoa học giúp con người hạnh phúc! [7]). Tuy nhiên, còn một yếu tố nữa mà chắc là ngày nay được quan tâm rất nhiều, do sự khao khát gia tăng: thành công. Trên Forbes năm 2018, Cohen [8] giải thích đủ để độc giả thấy lý do căn bản vì sao người có thái độ và suy nghĩ biết ơn sẽ có khuynh hướng đạt được thành công. Trong bài, tác giả dẫn lời Oprah Winfrey:

"Opportunities, relationships, even money flowed my way when I learned to be grateful no matter what happened in my life."

(Tạm dịch: Cơ hội, các môi quan hệ, và thậm chí cả tiên bạc chảy đến theo cách tôi muôn khi tôi học được cách biêt on bất kể chuyện gì xảy ra trong đời.)

Thật là một kết luận mạnh tới mức đáng kinh ngạc. Và có thể là vô giá nhất là nếu ta chưa từng hiểu sức mạnh của lòng biết ơn. Quả thật, nếu tồn tại thiếu sót này trong văn 
hóa con người, thì đây là khiếm khuyết quá lớn và không thể nào bù đắp bằng thư gì khác được cả.

Tuy vậy, với những công việc mà buộc phải viện dẫn tới đóng góp lịch sử của cụ Markov mà các nẻo đời đã dẫn qua, thì chẳng cần biết tới cái gọi là science of gratitude, tôi vẫn một mực biết ơn nhà toán học Andrey Markov. Nhưng hiểu hơn về science of gratitude lại mở ra một cách nhìn khác: Trong cuộc đời, có rất nhiều khả năng đã chưa thực hành và suy nghĩ biết ơn đủ và đúng mức với rất nhiều người, nhiều sự kiện, cho dù đó là hay hay dở, may hay không may, được hay mất...

Một giáo sư, đồng nghiệp nghiên cứu của tôi có lần đặt ra một câu hỏi vô cùng lý thú sau khi nghiên cứu về serendipity đã xuất bản [9] và đã có những ghi nhận giá trị từ cộng đồng nghiên cứu, đại ý như sau:

Với nhũung thứ có được, hoặc bị mất đi do khoảnh khắc xuất hiện hiển hiện mà bỏ lỡ, thì có thể hình dung giá trị được/mât. Thếnhưng, với nhũung thú mà còn không cả biêt đên sụ đã tì̀ng tồn tại của cơ hội, và mất đi còn không hề biêt, thì làm thế nào để nhận biêt được múc độ tôn thất?

Quả thật là đã gần 10 năm trôi qua sau khi biết đến câu hỏi (xin chân thành cảm ơn GS Napier), vẫn không có cách nào tìm được câu trả lời, nhưng ít nhất cũng có được kết quả ứng dụng cho vấn đề đang ngẫm nghĩ:

Nếu đó là đánh mất lòng biêt ơn thì hậu quả nhiêu khả năng sẽ là đánh mất co hội hoàn thành tâm nguyện trọn đời.

Tôi ghi nhớ việc tìm đến kết luận này cho bản thân mình, và cũng xem nó như lời răn dậy bản thân. Theo cách gián tiếp, Andrey Markov đã dậy thêm một bài học vô giá, suốt cuộc đời, về giá trị của lòng biết ơn.

\section{References}

[1] Wikipedia. (2022). Andrey Markov. Retrieved from: https://en.wikipedia.org/wiki/Andrey Markov 
[2] Vuong, Q. H. (2001). Black-Scholes PDE: A finance application. International Conference on Differential Equations, Approximations and Applications, DEAA - 2001 (pg. 53). Vietnam National University, Hanoi.

[3] Van Huu, N., Hoang, V. Q., \& Ngoc, T. M. (2005). Central Limit Theorem for Functional of Jump Markov Processes. Vietnam Journal of Mathematics, 33(4), 443461.

[4] Van Huu, N., \& Hoang, V. Q. (2007). On the martingale representation theorem and on approximate hedging a contingent claim in the minimum deviation square criterion. In: Some Topics in Industrial and Applied Mathematics (pp. 134-151). Singapore: World Scientific.

[5] La, V. P., \& Vuong, Q. H. (2019). bayesvl: Visually Learning the Graphical Structure of Bayesian Networks and Performing MCMC with 'Stan'. The Comprehensive $R$ Archive Network (CRAN). Retrieved from: https://CRAN.Rproject.org/package=bayesvl

[6] Kleiman, E. M., Adams, L. M., Kashdan, T. B., \& Riskind, J. H. (2013). Gratitude and grit indirectly reduce risk of suicidal ideations by enhancing meaning in life: Evidence for a mediated moderation model. Journal of Research in Personality, 47(5), 539-546.

[7] Emmons, R. A. (2007). Thanks!: How the new science of gratitude can make you happier. Houghton Mifflin Harcourt.

[8] Cohen, J. (2018, Feb. 7). Why Grateful People Always Succeed. Forbes. Retrieved from: https://www.forbes.com/sites/jennifercohen/2018/02/07/why-gratefulpeople-always-succeed/?sh=3b0315b935bf

[9] Napier, N. K., \& Vuong, Q. H. (2013). Serendipity as a strategic advantage?. In: T. Wilkinson (ed.) Strategic Management in the 21st Century (pp. 175-199). Praeger/ABC-Clio. 